lating motion of the earth's crust are referred to by Mr. George Darwin in his Report to the British Association in 1882. One of them was made by M. Magnus Nyrén at Pulkova, who, when engaged in levelling the axis of a telescope, observed spontaneous oscillations in the bulb of the level.

This was on May Io (April 28), 1877. The complete period was about twenty seconds, the amplitude being $I^{\prime \prime} 5$ and $2^{\prime \prime}$. One hour and fourteen minutes before this he observes that there had been a severe earthquake at Iquique, the distance to which in a straight line was Io,600 kilometres, and on an arc of a great circle 12,500 kilometres.

On September $20(8)$ in $1867 \mathrm{Mr}$. Wagner had observed at Pulkova oscillations of $3^{\prime \prime}$, seven minutes before which there had been an earthquake at Malta.

On April 4 (March 23), I868, an agitation of the level had been observed by M. Gromadzki, five minutes before which there had been an earthquake in Turkestan.

Similar observations had been made twice before. These, however, had not been connected with any earthquakes, at least--Mr. Darwin remarks-with certainty.

Like phenomena are mentioned by M. S. di Rossi, in his "Meteorologica Endogena."

Thus on March $20,188 \mathrm{r}$, at 9 p.m, a watchmaker in Buenos Ayres observed that all his clocks oscillating north and south suddenly began to increase their amplitude, until some of them became twice as great as before. Similar observations were made in all the other shops. No motion of the errth was detected. Subsequently it was learnt that this corresponded with an earthquake in Santiago and Mendeza.

Another remarkable example illustrating the like phenomena are the observations which were made on December 2I, I860, by means of a barometer in San Francisco, which oscillated, with periods of rest, for half an hour. No shock was felt, nor is it likely that it was a local accident, as it could not be produced artificially. On the following day, however, a violent earthquake was experienced at Santiago.

This brings me to the end of the few important illustrations of the phenomena of earth pulsations which I have at my disposal. With a little trouble I have no doubt that these might be greatly multiplied. As they stand, however, I think that they are quite sufficient to convince us of the existence of phenomena which hitherto have been almost entirely overlooked. That disturbances of the vertical are from time to time produced by long pulse-like waves can, with these examples before us, hardly be doubted. It must, however, be noted that they are of a different order to those phenomena which were so carefully sought for by the Darwins at Cambridge.

Tokio, Japan

\section{ON THE SUPPOSED HUMAN FOOTPRINTS RECENTLY FOUND IN NEVADA 1}

DRING the past summer various accounts have been published of the discovery of human footprints in sandstone rear Carson, Nevada. The locality is in the yard of the State prison, and the tracks were uncovered in quarrying stone for building purposes. Many different kinds of tracks were found, some of which were made by an animal allied to the elephant; some resembled those of the horse and the deer; others were apparently made by a wolf. There were also tracks made by large birds.

The footprints occur in series, and are all nearly in the same horizon. Some of the smaller tracks are sharp and distinct, but most of the impressions are indefinite in outline, owing apparently to the fact that the exact surface on which they were made is not usually exposed.

1 Abstract of a paper read before the National Academy of Sciences, at New York, November 57, r882.
The supposed buman footprints are in six series, each with alternate right and left tracks. The stride is from two and a half to over three feet in extent. The individual footprints are from eighteen to twenty inches in length, and about eight inches wide. The distance between the line of right-hand and left-hand tracks, or the straddle, is eighteen to nineteen inches.

The form and general appearance of the supposed human tracks is shown in Fig. 2, which is a reduced copy of one of the impressions represented by Dr. W. H. Harkness, in his paper before the California Academy of Sciences, August 7, I882. The shaded portion was restored by him from other footprints of the series. A

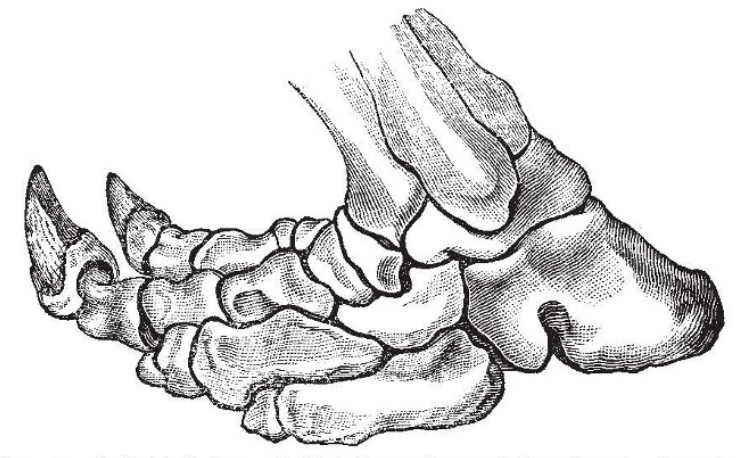

FIG. x.- Left hind foot of Mylodon robustus (after Owen). One-sixth natural size.

copy of this impression was given also by Prof. Joseph Le Conte, in his paper before the same Society, August 27, I882.

The size of these footprints, and especially the width between the right and left series, are strong evidence that they were not made by men, as has been so generally supposed.

A more probable explanation is that the impressions are the tracks of a large sloth, either Mylodon or Morotherium, remains of which have been found in essentially the same horizon. In support of this view it may be said that the footprints are almost exactly what these animals would make if the hind feet covered the impressions of

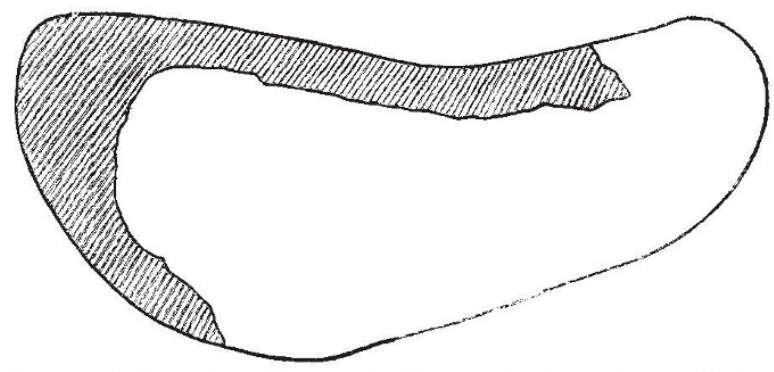

Fig. 2. - Left footprint at Carson (after Harkness). One-sixth natural size.

those in front. In size, in stride, and in width between the right and left series of impressions, the footprints agree closely with what we should expect Mylodon or Morotherium to make. In Fig. I the bones of the left hind foot of a species of Mylodon are represented, the figure being reduced to the same scale as the accompanying cut, Fig. 2, of one of the supposed human footprints.

The geological horizon of these interesting footprints is near the junction of the Pliocene and Quaternary. The evidence, at present, appears to point to the Equus beds of the upper Pliocene as the nearest equivalent.

Since the above communication was read, the writer has had an opportunity of examining photographs and casts of the Carson footprints, and is confirmed in his opinion that the supposed human tracks were made by large 
Edentates. The important fast has recently been determined that some of these tracks show impressions of the fore feet. The latter are somewhat outside of the large footprints, as would naturally be the case if the animal changed its course.

O. C. MARSH

\section{WINTER LIFE AT FORT RAE}

$\mathrm{I} \mathrm{T}$ was not until the bexinning of December that our winter really set in, but when it did so tliere was no mistake about it, as the Ist of the month began with the thermometer at $-34^{\circ}$, and except for some mild weather at Christmas, the cold continued through that month. January was colder still, the thermometer once or twice approaching $-50^{\circ}$, but in the early part of February a violent storm was accompanied by a remarkable rise of temperature $\left(\right.$ to $\left.+20^{\circ}\right)$, and followed by some mild weather, since which the thermometer has again fallen, reaching $-39^{\circ}$ a couple of days ago.

This, however, I atn informed by the inhabitants, is the mildest winter that has been known for many years, and I have no doubt that a temperature of $-60^{\circ}$ is not unconimon in severe winters.

It is strange how much less one feels this extreme cold than might be imagined. For the first day or two it was unpleasant, but after that the systen seemed to accommodate itself to it, so that a day when the temperature was anywhere above $-15^{\circ}$ felt quite warm and pleasant. To-day, for instance, I am writing with my window open, although the thermometer is several degrees below zero, and there is a light breeze. There have been days, it is true, when-with the thermometer near $-30^{\circ}$, and a strong breeze blowing, filling the air with snowdrift like a dense fog--outdoor exercise was most unpleasant, probably resulting in a frozen face, but such days were not very numerous, a strong wind, even from the cold quarter (the north-west), sending the temperature up in a way that I cannot quite account for.

Now the climate reminds me of Davos Platz, the sun having considerable power ; there is, however, more wind. Yesterday the black bulb in vacuo read $82^{\circ}$. The only drawback is the intense glare from the snow, which makes coloured spectacles a necessity.

During the first part of the winter we were a little anxious about food, not that we were in any danger of starvation, as the Indians had brought in quantities of dried meat in the autumn, but dried meat is a most unpalatable article of diet, and requires strong teeth and a strong digestion; and then the fishery was not as productive as usual, and the daily produce of the nets (which are set under the ice) was gradually diminishing. At last, however, the deer made their appearance some forty miles from this, and since then our supplies of fresh meat have come in regularly. Rabbits, too, have lately become most numerous. These animals are the great resource of the Indians in times of scarcity, but they are not always plentiful. They are said to attain their maximum once in ten years, whell they seem to suffer from a disease which shows itself in lumps on their heads; the following year there is hardly a rabbit to be seen, and then they gradually increase for another ten years.

The winter has passed very uneventfully. On November I 7 and two or three following days there were magnetic disturbances of great violence, due, no doubt, to the large sunspot. The displays of aurora at that time, however, were not of any remarkable brilliancy; we have had far brighter ones since, with far less magnetic disturbance. But as a rule the auroras have not been remarkable, though a night seldom or never passes without more or less-the brilliant coloured ones one reads about are conspicuous by their absence. For the most part they are all of the same yellowish colour, showing the single characteristic bright line in the spectroscope, but a bright aurora usually shows more or less prismatic colouring along the lower edge, with a spectrum sometimes of one or two additional bright lines, as a rule towards the violet end of the spectrum, though on one occasion I observed a bright band in the red.

Aurora is very rarely seen until night has quite set in, but on three occasions we have seen it shortly after sunset, and on these occasions it was of a reddish or copper colour, as though partly coloured by the sun's light ; it must, I think, have been associated with thin cloud. Its motion and shape showed it to be aurora.

The terrestrial radiation therinometer placed on the snow generally showed a depression of from $10^{\circ}$ to $20^{\circ}$ on: every calm, clear day throughout the winter, even by day when sheltered from the sun. The lowest reading; were, as might be expected, with the dry north-west wind. Sometimes the first warning of an impending change of wind to the south-east was given by a rise of this thermometer before the barometer was affected.

A thermometer suspented on the outer wall of the observatory at times read $9^{\circ}$ or $10^{\circ}$ lower than one in the screen, owing to radiation, and I think that the common practice of exposing unsheltered thermometers may explain some of the low temperatures sometimes reported from this country.

Our daily routine of observations goes on very regularly. Lately wolves have taken to prowling about the neighbourhood, and the observer on duty goes to visit the thermometers armed with a huge club; of course a gun or axe cannot be allowed near the observatory on account of the magnetic instruments.

A remarkable epidemic of influenza made its appearance here in January. We first heard of it among the Indians far to the north-west of this. When it arrived here it attacked every soul in the place-- Indians and whites-fortunately in a very mild form, and we hear that Fort Simpson, on the Mackenzie, suffered in the same way. Such an occurrence is most unusual in this country. With this exception we have all enjoyed good health.

We expect the ice to break up about the middle of June, and then will come the reign of the mosquitoes, which make the summer the most disagreeable season of the year in this coututry. Fortunately they do not last long in this latitude, and by the end of August, when we set out on our homeward journey, they will be over.

Fort Rae, March 25

HENRY P. DAWSON

\section{THE NORWEGIAN NORTH-SEA EXPEDITION ${ }^{1}$}

II.

D. MOHN continues his description of Jan Mayen Island as follows :-

"The northern part of Jan Mayen is larger and more elevated than the southern. From its central tract towers the monarch of the island, Mount Beerenberg, an extinct volcano, rising in regal majesty to the height of 6400 feet. The crater measures 4360 feet in diameter. The upper cone, which shelves at an angle of $42^{\circ}$ and attains an altitude of about 2000 feet, would, to julge from the black spots so conspicuous on its western declivity, appear to be composed of ashes. The base supporting the cone slopes out in every direction at an angle of from 8 to ro degrees, and this incline is retained towards the north and east to a depth of at least 1000 fathoms beneath the sea-level. The edge of the crater has a jagged appearance, and the loftiest peak lies on the west side of the mountain Towards the north the wall of the crater has partially given way down to a height of from 600 to 700 feet. The depression thus formed extends northwards towards the north coast of the island, bounded on either side by diverging mountain ridges, that here and there project ledge-like one above the other. This is BeerenI Concluded frum p. 350 . 